PUBLIKAUMA: Jurnal Ilmu Administrasi Publik UMA, 9 (1) (2021): 67-74

DOI: https://doi.org/10.31289/publika.v9i1.5197

PUBLIKAUMA: Jurnal Ilmu Administrasi Publik

Available online http://ojs.uma.ac.id/index.php/publikauma

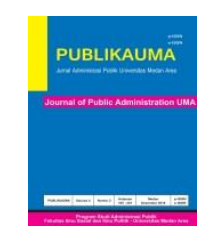

\title{
Implementasi Sociopreneurship Berbasis Lingkungan Sebagai Reduksi Pengangguran Di Kota Mataram
}

\author{
Mey Susanti AS* \\ Prodi Ilmu Administrasi Negara, Sekolah Tinggi Ilmu Administrasi, Indonesia
}

Disetujui: Maret 2021; Direview: April 2021;Diterima: Mei 2021

\begin{abstract}
Abstrak
Tujuan kajian ini adalah untuk menggambarkan potensi aktivitas sociopreneurship berbasis lingkungan dalam mereduksi pengangguran di perkotaan melalui gagasannya dalam pengembangan kawasan ekowisata penangkaran penyu Pantai Mapak Indah, Kota Mataram Provinsi NTB. Penelitian ini dikategorikan dalam jenis kualitatif dengan pendekatan studi kasus, tahapan pertama dalam penelitian ini adalah observasi sekaligus menentukan informan sampling sociopreneur yang sukses, tahapan kedua adalah wawancara atau pengumpulan data terhadap informan dilakukan pada tokoh utama sebagai inisiator dan sejumlah individu yang terhubung dalam jaringan aktivitas sociopreneur, yaitu warga masyarakat yang berdomisili di wilayah pantai Mapak Indah. Tahapan ketiga adalah dokumentasi agar data yang diterima tidak hilang dan dapat diambil kapan saja dibutuhkan. Dan tahap terakhir adalah analisis data, pada tahapan ini dilakukan proses validasi temuan data penelitian. Hasil penelitian menunjukkan bahwa implementasi sociopreneurship berbasis lingkungan melalui pengembangan ekowisata penangkaran penyu di wilayah Kota Mataram mulai berkembang atas inisiatif dari satu orang atau sekelompok orang yang memiliki keinginan yang kuat untuk membantu memecahkan permasalahan ekonomi dan lapangan pekerjaan sebagai dampak dari adanya bonus demografi yang terjadi di perkotaan dengan kontribusi modal sosial di sekitar, saling timbal balik, dan berkelanjutan, dan untuk menghasilkan jasa yang bernilai ekonomis bagi masyarakat sekitar, terlihat berhasil.
\end{abstract}

Kata Kunci: Bonus Demografi, Pengangguran Terdidik, Sociopreneurship.

\begin{abstract}
The purpose of this study is to describe the potential of environmental-based sociopreneurship activities in reducing unemployment in urban areas through the idea of developing an ecotourism area for turtle breeding at Mapak Indah Beach, Mataram City, NTB Province. This research is categorized in a qualitative type with a case study approach, the first stage in this research is observation and at the same time determining the successful sociopreneur sampling informants, the second stage is interviews or data collection on informants carried out on the main character as the initiator and a number of individuals who are connected in the sociopreneur activity network, namely community members who live in the coastal area of Mapak Indah. The third stage is documentation so that the data received is not lost and can be retrieved whenever needed. And the last stage is data analysis, at this stage the validation process of research data findings is carried out. The results showed that the implementation of environ mentallybased sociopreneurship through the development of turtle breeding ecotourism in the Mataram City area began to develop at the initiative of one person or group of people who had a strong desire to help solve economic problems and employment opportunities as a result of the demographic bonus that occurred in urban areas. with the contribution of social capital around, reciprocal, and sustainable, and to produce services that have economic value for the surrounding community, looks successful.
\end{abstract}

Keywords: Demographic Bonus, Educated Unemployment, Sociopreneurship.

How to Cite: AS, S.M. (2021). Implementasi Sociopreneurship Berbasis Lingkungan Sebagai Reduksi Pengangguran Di Kota Mataram. PUBLIKAUMA: Jurnal Ilmu Administrasi Publik UMA, 9 (1): 67-74

${ }^{*}$ Corresponding author: ISSN 2549-9165 (Print)

E-mail: $\underline{\text { meysusanti.as@gmail.com }}$ ISSN 2580-2011 (Online) 


\section{PENDAHULUAN}

Indonesia mengalami transisi demografi yang cepat sejak tahun 1971 hingga saat ini, perubahan transisi ini mengarah pada situasi yang disebut bonus demografi. Bonus demografi adalah suatu kondisi perubahan struktur kependudukan yang ditandai dengan angka kelahiran dan kematian rendah (Irianto, 2016).

Apabila melihat realita sekarang ini, Indonesia diperkirakan mencapai puncak bonus demografi pada 2017 sampai 2019 untuk gelombang pertama dan 2020 sampai 2030 untuk gelombang bonus demografi kedua. Hal ini berarti komposisi jumlah penduduk dengan usia produktif 15-64 tahun mencapai titik maksimal jika dibandingkan dengan usia non-produktif 0-14 tahun dan 65 tahun ke atas. Dengan kata lain, telah terjadi kenaikan jumlah angkatan kerja potensial (Jati, 2015).

Jika diperhatikan lebih seksama, bonus demografi akan menjadi andalan peningkatan produktifitas suatu Negara dan menjadi sumber pertumbuhan ekonomi dengan pemanfaatan sumber daya manusia yang produktif, dimana penduduk usia produktif tersebut mampu menghasilkan pendapatan untuk memenuhi kebutuhan konsumsi mereka dan memiliki tabungan yang dapat dijadikan investasi. Akan tetapi jika yang terjadi adalah sebaliknya, dimana penduduk usia produktif yang jumlahnya besar, tidak terserap oleh lapangan pekerjaan yang tersedia, maka akan menjadi beban ekonomi karena akan menjadi beban bagi penduduk yang bekerja dan akan memicu terjadinya angka pengangguran yang tinggi (Maryati, 2015).

Karakteristik dari pengangguran yang ada di Indonesia salah satunya adalah tingginya pengangguran dengan pendidikan tinggi atau disebut juga dengan pengangguran terdidik (dengan pendidikan minimal Sekolah Menengah Atas) (Pratomo, 2017). Pengangguran di Indonesia berdasarkan data Survei Angkatan Kerja Nasional tahun 2016 didominasi oleh angkatan kerja dengan pendidikan sekolah menengah atas (baik umum maupun kejuruan) dan pendidikan tinggi (sarjana dan diploma). Artinya bahwa semakin tinggi pendidikan seseorang, probabilitas atau kemungkinan menjadi penganggur pun semakin tinggi (Nur Asnawi, 2005), fenomena yang demikian ini sangat ironis. Penelitian dari Allen (Allen, 2016) menunjukkan bahwa sepertiga dari penganggur terutama pada usia muda dan berpendidikan (Sekolah Menengah Atas, diploma dan sarjana), harus menunggu selama satu tahun, untuk dapat masuk pasar kerja sektor formal. Hal ini disebabkan oleh ketidakseimbangan antara pertumbuhan angkatan kerja muda berpendidikan dengan lingkup pasar kerja sektor formal yang tersedia. Mereka ini lah yang kemudian disebut dengan istilah "choosy educated job seekers".

Saat ini krisis yang terjadi di perkotaan tidak hanya terkait dengan masalah ekonomi, seperti kemiskinan, pengangguran, tuna wisma dan anak jalanan, tetapi krisis perkotaan juga meliputi krisis keamanan, krisis lingkungan, energi dan sosial (Saputro, 2020).

Pada Agustus 2019, jumlah penduduk Provinsi NTB berdasarkan hasil proyeksi penduduk 2010-2035 diperkirakan mencapai 5 juta orang, dengan jumlah penduduk usia kerja (15 tahun ke atas) sebanyak 3,6 juta. Dari seluruh penduduk usia kerja, sekitar 68,65 persen merupakan angkatan kerja dan 31,35 persen bukan angkatan kerja. Jumlah penduduk yang bekerja pada Agustus 2019 sebanyak 2,4 juta (sekitar 96,58 persen dari seluruh angkatan kerja) dan sisanya sekitar 3,42 persen merupakan penganggur. Persentase pengangguran tersebut disebut juga sebagai Tingkat Pengangguran Terbuka (TPT). TPT merupakan indikator ukuran keberhasilan pemerintah dalam mengurangi jumlah pengangguran.

Tingkat pengangguran terbuka (TPT) di Provinsi NTB pada Agustus 2020 sebesar 4,22 persen atau 113.430 orang. Tingkat pengangguran naik sebesar 0,94 persen dibandingkan Agustus 2019. Dari 10 kabuaten/kota di Provinsi NTB, tingkat pengangguran terbuka yang tertinggi berada di Kota Mataram sebesar 6,83 persen. Sedangkan yang terendah di Kabupaten Bima sebesar 2,89 persen (BPS Provinsi Nusa Tenggara Barat, 2020).

Salah satu solusi pengentas kemiskinan dan pengangguran efektif dunia adalah dengan 
berwirausaha (entrepreneurship). Upaya penyelesaian masalah sosial dengan menggunakan pendekatan kewirausahaan merupakan terobosan yang luar biasa. Melalui aksi kewirausahaan mampu mereduksi jumlah kemiskinan dan membuka lapangan kerja (Putri, 2017).

Istilah sociopreneur mulai menjadi trend di kalangan anak muda. Penelitian (Suyatna \& Nurhasanah, 2018) menunjukkan bahwa pemuda dengan berbagai teknologi yang sangat cepat dan canggih telah mulai mencari peluang bisnis sosial sebagai pilihan bertahan hidup di tengah kesempitan mereka dalam mencari pekerjaan.

Dalam menguraikan konsep sociopreneurship atau kewirausahaan sosial, peneliti menggunakan Empat Elemen Utama dalam kewirausahaan sosial (Hulgard, 2010) yaitu Nilai Sosial (social value); Masyarakat Sipil (civil society); Inovasi (innovation); dan Kegiatan Ekonomi (economic activity). Social Value adalah adanya manfaat sosial yang nyata bagi masyarakat dan lingkungan sekitar, Civil Society merupakan bentuk inisiatif dan partisipasi masyarakat sipil dengan mengoptimalkan modal sosial yang ada di masyarakat, Innovation merupakan inovasi yang dilakukan dalam pemecahan masalah dengan melihat kearifan lokal masyarakat, sedangkan Economic Activity merupakan keseimbangan antara aktivitas sosial dan aktivitas bisnis untuk menjamin kemandirian dan keberlanjutan misi sosial organisasi (Lak lak Nazhat El Hasanah, 2018).

Berdasarkan fenomena, serta uraian empiris dan teoritis, tujuan penelitian ini adalah untuk menggambarkan potensi aktivitas sociopreneurship berbasis lingkungan dalam mereduksi pengangguran di Kota Mataram melalui kegiatan pengembangan ekowisata penangkaran penyu Pantai Mapak Indah.

\section{METODE PENELITIAN}

Penelitian ini dikategorikan dalam jenis kualitatif dengan pendekatan studi kasus. Menggunakan studi kasus tepat untuk situasi yang masih berjalan sampai saat ini. Selama isu suatu kasus masih berkembang, teori masih harus diperbantukan untuk menentukan arah studi (Creswell, 2015).

Adapun pada tahapan pertama dalam penelitian ini adalah observasi sekaligus menentukan informan sampling sociopreneur yang sukses secara purposif. Sebagai salah satu daerah destinasi wisata yang penting di Indonesia, pulau Lombok diperkaya oleh keberadaan aktivitas sociopreneneur di bidang pariwisata. Data yang diperoleh berupa catatan wawancara, catatan observasi, dokumen pribadi dari sociopreneur, foto-foto dan dokumen publik lainnya seperti berita di media massa, serta kajian literatur berupa jurnal dan buku yang memberikan dasar konseptual mengenai sociopreneur sebagai pengembangan konsep new public governance yang dikenal dalam bidang ilmu administrasi publik maupun ilmu sosial lainnya secara luas. Observasi juga dilakukan untuk melihat permasalahan yang ada, mengidentifikasi masalah yang ada dalam konteks sociopreneurship.

Tahapan kedua adalah wawancara atau pengumpulan data. Wawancara terhadap informan dilakukan pada tokoh utama sebagai inisiator dan sejumlah individu yang terhubung dalam jaringan aktivitas sociopreneur, yaitu warga masyarakat yang berdomisili di wilayah pantai Mapak Indah. Tahapan ketiga adalah dokumentasi agar data yang diterima tidak hilang dan dapat diambil kapan saja dibutuhkan.

Pada tahap terakhir adalah tahap analisis data, pada tahapan ini dilakukan proses validasi temuan data penelitian. Proses validasi menggunakan triangulasi agar data yang diperoleh dapat valid sesuai dengan hasil temuan di lapangan.

\section{HASIL DAN PEMBAHASAN}

Implementasi Sociopreneurship

Di Provinsi Nusa Tenggara Barat, belum tersedia basis data wirausaha sosial selain buku-buku, jurnal, laporan dan berita tentang sosok kasuistik wirausaha sosial sukses yang memotivasi dan menginspirasi. Bisa jadi hal ini dikarenakan tokoh-tokoh tersebut memang tidak mengutamakan pencitraan dibandingkan gerakan itu sendiri.

Salah satu pengaruh dari kewirausahaan sosial adalah terciptanya lapangan kerja bagi mereka yang tidak memiliki kesempatan kerja. Menjadi sociopreneur tidak selalu 
membutuhkan banyak modal untuk memulai. Inovasi yang berkelanjutan menjadi kunci sukses dari gerakan sosial ini. Format yang ditawarkan oleh sociopreneurship juga mengandung promosi kesetaraan gender, seluruh masyarakat berhak ikut andil dalam aktivitas ini tanpa batasan jenis kelamin (Listyorini, 2012). Serta yang tidak kalah penting dari dampak sociopreneurship adalah ikut dalam pelestarian budaya, dimana beberapa jenis usaha yang digeluti menyesuaikan dengan sumber daya alam dan manusia setempat, sehingga kearifan lokal dapat sekaligus mengenalkan potensi-potensi daerah pada khalayak umum. Pemanfaatan tidak dilakukan sebebas-bebasnya, melainkan pemanfaatan dilakukan dengan melakukan pemeliharaan sumber daya dan mencegah eksploitasi.

Kewirausahaan sosial diharapkan menjadi solusi alternatif yang inovatif karena tidak hanya berfokus pada keuntungan, akan tetapi juga kesejahteraan masyarakat. Kewirausahaan sosial dapat membantu menyelesaikan masalah ekonomi Indonesia. Masyarakat akan berpartisipasi langsung dengan menjadi pelaku bisnis dan keuntungannya akan dikembalikan ke masyarakat untuk dapat dikembangkan lagi. Tujuan jangka panjangnya adalah agar kewirausahaan sosial dapat membantu masyarakat menjadi lebih mandiri secara finansial, sehingga mereka tidak selalu harus bergantung pada kebijakan pemerintah yang biasanya merupakan "pemanis buatan", seperti subsidi dan bantuan langsung tunai.

Kaum muda saat ini memiliki potensi jika akses kreativitas diberikan oleh lingkungan sosial di sekitarnya, Mahendra Irawan atau akrab dipanggil dengan $H$. Awan sebagai seorang sociopreneur, berangkat dari kondisinya yang belum mendapat pekerjaan tetap, H. Awan kemudian memanfaatkan lahan pribadinya yang berada di pinggiran Pantai Mapak Indah, Kota Mataram untuk berjualan. H. Awan melihat kawasan tempat berjualannya memiliki sumber daya yang strategis bagi wisatawan dengan pengalaman yang unik.

Terletak di daerah pesisir bagian selatan Kota Mataram, kawasan wisata Pantai Mapak Indah ini telah menjadi salah satu obyek daya tarik wisata dan menarik untuk dilakukan suatu studi bagi kemungkinan pengembangannya. Awal mula H. Awan membuat penangkaran bagi penyu karena merasa kasihan melihat nasib dari jenis hewan biota laut yang dilindungi itu. Banyak warga di sekitar lingkungan Pantai Mapak Indah yang menyia-nyiakan keberlangsungan hidup anak tukik tersebut. Biasanya pada bulan Juni, Juli sampai Agustus saat musim bertelur, setiap pagi warga sekitar pantai akan banyak menemukan telur-telur penyu di pinggir pantai Mapak Indah. Masyarakat sekitar tidak tahu cara memanfaatkan hewan langka ini. Telur-telur tersebut banyak dijadikan mainan, bahkan ada juga yang membawa telur ini untuk dijual ke pasar. Pada tahun $2016 \mathrm{H}$. Awan berinisiatif mengajak masyarakat sekitar wilayah Pantai Mapak Indah untuk membuat kelompok yang membudidayakan penyu di lokasi warung tempatnya berjualan kuliner khas Lombok. Ia kemudian membuat kolam kecil untuk menampung telur tukik yang sudah menetas. H. Awan harus bersabar merawat biji-biji telur penyu itu agar bisa menetas dengan selamat selama satu setengah bulan lamanya. Satu induk penyu rata-rata mampu menghasilkan minimal 50 butir telur. Telur-telur tersebut selanjutnya dipisahkan per satu induk dan diberi tanda pada ruang lingkaran kawat berukuran setengah meter.

Ketika anak tukik telah berusia 3 bulan, $\mathrm{H}$ Awan akan mengundang warga sekitar pantai untuk menyaksikan pelepasan anak tukik ke habitatnya semula. Dan jika sudah dewasa, penyu-penyu betina tersebut akan kembali pulang ke pantai Mapak Indah untuk menitipkan puluhan butir telurnya. $\mathrm{H}$ Awan rela begadang tiap bulan Juni, Juli dan Agustus, ia akan menghabiskan waktunya dari jam 9 malam hingga jam 5 dini hari hanya untuk menunggui dari jauh sekawanan penyu betina yang datang bertelur di pantai Mapak Indah. Hal ini dilakukan sebagai upaya untuk memberikan kesadaran kepada masyarakat terhadap kelestarian penyu. Melalui kegiatannya ini, ia mengedukasi masyarakat sekitar sehingga diharapkan dapat mengurangi kegiatan wisata yang berpotensi mengundang keramaian, yang hanya akan menimbulkan banyak sampah.

Kota Mataram sendiri saat ini belum memiliki jenis pariwisata yang memadukan 
antara kegiatan ekonomi dengan ekologi. Daripada uang para pengunjung yang datang ke pantai dipergunakan hanya untuk membeli makanan saja, lebih baik diarahkan untuk berdonasi dengan melepaskan anak penyu ke habitatnya di laut. Harapan ke depannya akan adanya kerja sama dengan beberapa instansi pendidikan untuk lebih memperkenalkan tentang wisata ini serta memberikan pengetahuan terkait dengan penyu. Potensi ekowisata penangkaran telur penyu di kawasan Mapak Indah memang cukup bagus dan sangat memungkinkan pengembangannya menjadi sebuah objek wisata konservasi penyu. Ditambah dengan melihat keseriusan dan komitmen dari warga sekitar untuk menjaga keberlanjutan hewan langka yang dilindungi itu cukup tinggi. Di bawah binaan BPSPL Denpasar Wilayah Kerja NTB, Kelompok Pelestari Penyu Mapak terbentuk pada 2017 sebagai salah satu upaya untuk meningkatkan kepedulian masyarakat.

Sociopreneurship Berbasis Lingkungan

Sociopreneur secara istilah merupakan pelaku wirausaha yang social driven, dengan misi untuk mengatasi masalah sosial yang ada, serta tidak dimotivasi profit. Mereka adalah orang-orang yang berupaya menciptakan perubahan positif atas persoalan yang menimpa masyarakat, baik itu bidang pendidikan, kesehatan, ataupun masalah kemasyarakatan lain, terutama ekonomi secara entrepreneurially, atau dengan kata lain wirausaha yang ulet serta berani ambil risiko. Hal ini diungkapkan oleh J.G. Dees (Dees, 2018) dalam Ratna dan Meily (Widiastuti \& Margaretha, 2011), bahwa orang-orang memiliki jiwa sociopreneur disebut sebagai "spesies khusus" dalam genus wirausaha. Sociopreneurship pada dasarnya tidak memiliki batas pada suatu aksi sosial dari sebuah lembaga, organisasi atau perusahaan melalui program CSR, Corporate Social Responsibility atau lembaga sosial lainnya. Spirit entrepreneurship-nya lebih bersifat pada mental atau sikap terhadap suatu personal atau masyarakatnya.

Social Entrepreneur sederhananya adalah seseorang yang mengerti permasalahan sosial dan menggunakan kemampuan entrepreneurship-nya untuk melakukan perubahan sosial, terutama meliputi bidang kesejahteraan, pendidikan dan kesehatan. Jika entrepreneurship mengukur keberhasilan dari kinerja keuangannya (keuntungan ataupun pendapatan) maka sociopreneur keberhasilannya diukur dari manfaat yang dirasakan oleh masyarakat (Santosa, 2007).

Diawali dengan keprihatinan terhadap keadaan sosial, kewirausahaan sosial yang merupakan kombinasi dari semangat besar dalam misi sosial dengan disiplin, inovasi dan keteguhan sebagaimana lazim ditemukan dalam dunia bisnis. Sehingga dapat dikatakan bahwa kewirausahaan sosial menggunakan sikap mental wirausaha demi tujuan-tujuan sosial. Mereka sering diberi julukan "change maker", yang menandakan bahwa para tokoh sociopreneur adalah orang yang spesial.

Pengusaha sosial adalah orang-orang yang inovatif, termotivasi, dan berpikir kritis. Dalam penjelasan sistematis, (Hulgard, 2010) merumuskan konsep sociopreneur yang setidaknya terdiri dari empat elemen utama. Berdasarkan kajian terhadap tokoh sociopreneurship berbasis lingkungan pada penangkaran penyu pantai Mapak Indah, Kota Mataram, Empat Elemen Utama Sociopreneurship menurut Hulgard dijelaskan berikut ini :

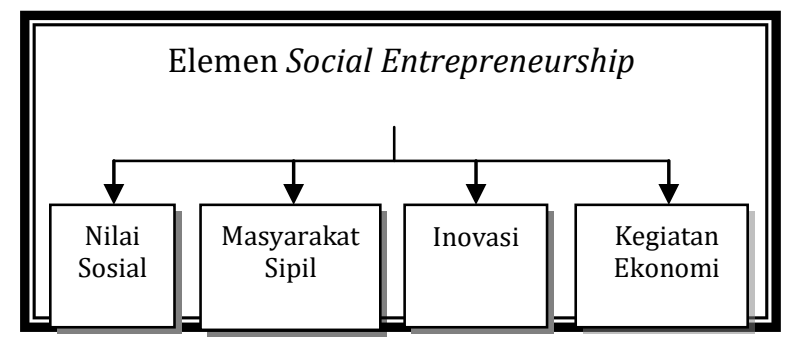

$$
\begin{aligned}
& \text { Gambar 1. Empat Elemen Utama } \\
& \text { Sociopreneurship } \\
& \text { menurut Hulgard (Hulgard, 2010) }
\end{aligned}
$$

Nilai Sosial (Social Value) Merupakan elemen utama dalam kewirausahaan sosial. Kawasan penangkaran penyu Pantai Mapak Indah, Kota Mataram memiliki nilai manfaat sosial yang nyata bagi masyarakat di sekitarnya, baik secara langsung maupun tidak langsung, dimana masyarakat menjadi lebih peduli dengan lingkungannya, hal ini menjadi pembeda utama kewirausahaan sosial dengan jenis kewirausahaan lainnya. Selain itu nilai sosial lainnya dengan memberikan 
keterampilan dan kemampuan yang dimiliki kepada warga untuk memanfaatkan peluang bisnis dari potensi yang ada di Pantai Mapak Indah.

Masyarakat Sipil (Civil Society) Kewirausahaan sosial muncul dari inisiatif masyarakat lokal seperti $\mathrm{H}$. Awan dengan memanfaatkan modal sosial yang terdapat di lingkungan sekitar kawasan Pantai Mapak Indah, Kota Mataram. Kewirausahaan sosial ini berbeda dengan kewirausahaan pada umumnya yang berorientasi pada profit. $\mathrm{H}$. Awan melalui inisiatifnya mengajak masyarakat sekitar Pantai Mapak Indah untuk mengelola kawasan yang sering dikunjungi oleh penyu, dan manfaatnya kini dapat dirasakan oleh seluruh kelompok, bahkan juga dirasakan oleh masyarakat secara umum.

Inovasi (Innovation) Kewirausahaan sosial yang inovatif merupakan jiwa kewirausahaan yang dilandasi oleh ide-ide kreatif, digunakan untuk memecahkan masalah sosial, sehingga dapat memberikan dampak yang positif bagi banyak orang. Inovasi digunakan untuk menyelesaikan masalah sosial, bukan hanya untuk menghasilkan keuntungan yang tinggi. $\mathrm{H}$. Awan, yang merasa peduli untuk melindungi fauna laut terancam punah tersebut mulai melakukan aktivitas penangkaran penyu dan berinisiatif mengajak masyarakat sekitar wilayah Pantai Mapak Indah untuk membuat kelompok yang membudidayakan penyu dengan cara menjadikan lokasi tempatnya berjualan sebagai tempat penangkaran penyu. Visi, misi dan tujuan dari pengembangan kawasan ekowisata Pantai Mapak Indah adalah mewujudkan kesejahteraan masyarakat dengan mengembangkan ekowisata berbasis pelestarian penyu dan habitatnya. Hal ini dapat dicapai melalui misi-misi sebagai berikut : mengupayakan pelestarian populasi penyu dan habitatnya, penguatan kelembagaan pengelola kawasan, dan meningkatkan sosial ekonomi dan budaya masyarakat sekitar. SDM pengelola sampai saat ini berjumlah sekitar 50 orang yang tergabung dalam Komunitas Pecinta Penyu Mapak (KP2M), oleh H. Awan, SDM tersebut dibagi menjadi 3 (tiga) kelompok yaitu: POKDARWIS (Kelompok Sadar Wisata); POKMASWAS (Kelompok Masyarakat
Pengawas) dengan tanggungjawabnya dalam hal mengawasi, memelihara keharmonisasisan ekosistem dan alam, telah memiliki SK dari DKP Propinsi Nusa Tenggara Barat; dan POKLAHSAR (Kelompok Pengolah dan Pemasar) pengolahan dan pemasaran abon ikan laut.

Kegiatan Ekonomi (Economic Activity) Kewirausahaan sosial berbeda dengan organisasi kemasyarakatan, walaupun memiliki kemiripan dengan organisasi nirlaba, namun kewirausahaan sosial tidak bergantung pada pihak lain untuk menghimpun dana. Sesuai dengan tujuan pengembangan kewirausahaan sosial yaitu menyelesaikan masalah dengan bisnis, Keberadaan aktivitas bisnis merupakan pembeda antara kewirausahaan sosial dan organisasi sosial. Kegiatan komersial dari aktivitas bisnis yang dilakukan bertujuan untuk menciptakan kemandirian bagi komunitas / kelompok terkait. Tujuan dari aktivitas bisnis ini adalah sebagai penyeimbang dari aktivitas ekonomi dan sosial, dan bukan untuk memperoleh keuntungan. Aktifitas ekonomi pemberdayaan masyarakat di kawasan Pantai Mapak Indah melalui POKDARWIS (Kelompok Sadar Wisata) yang mengembangkan icon penyu dan melestarikan view dari Pantai Mapak Indah serta mengelola parkiran lokasi dan area kuliner dan POKLAHSAR (Kelompok Pengolah dan Pemasar) pengolahan dan pemasaran abon ikan laut, dengan label BERUGAQ ELEN (dalam bahasa Sasaq-Lombok, Berugak sejenis dengan gazebo dan Elen yang berarti sejuk) dan produk abon ini sudah memiliki izin usaha.

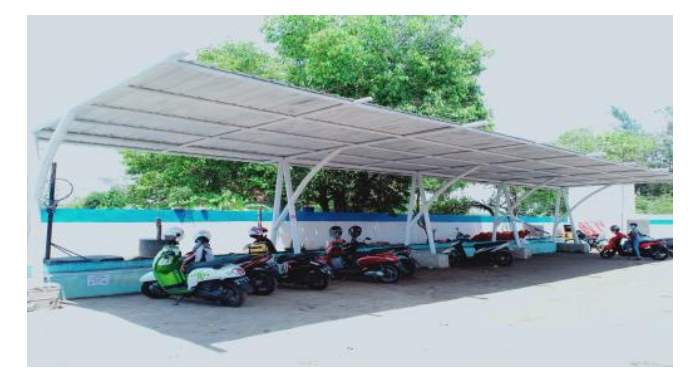




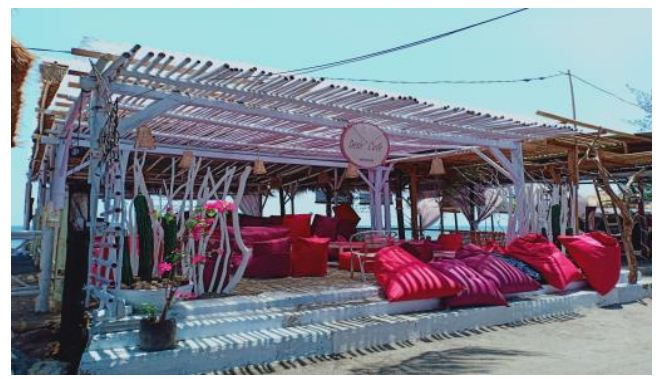

Gambar 2.

Kegiatan Ekonomi

(lahan parkir dan lokasi kuliner)

Sumber : Dokumen Pribadi, Juli 2020

\section{SIMPULAN}

Berdasarkan proses telaah dan analisis yang sudah dilakukan, beberapa kesimpulan yang diperoleh yakni : Pertama, Usaha yang dilakukan oleh sociopreneurship dengan kontribusi modal sosial di sekitar, saling timbal balik, dan berkelanjutan, dan dampaknya untuk menghasilkan jasa yang bernilai ekonomis bagi masyarakat sekitar melalui pengembangan ekowisata penangkaran penyu untuk mereduksi pengangguran di Kota Mataram terlihat berhasil; Kedua, Bonus demografi yang dirasakan saat ini menjadi momentum dalam pengembangan sociopreneurship. Adanya peluang yang dimiliki kaum muda untuk berkreasi di berbagai bidang sekaligus mengurangi ketimpangan ekonomi antar masyarakat merupakan sebuah tantangan serius serta sebagai pemantik munculnya wirausahawirausaha muda untuk mendukung pembangunan nasional.

\section{DAFTAR PUSTAKA}

Allen. (2016). Analysis of Trends and Challenges in the Indonesian Labor Market. Asian Development Bank (ADB) Paper on Indonesia, 16, 1-38.

BPS Provinsi Nusa Tenggara Barat. (2020). Profil Ketenagakerjaan Provinsi Nusa Tenggara Barat Berdasarkan Hasil Sakernas Agustus 2019.

Creswell, J. W. (2015). Penelitian Kualitatif \& Desain Research Memilih di Antara Lima Pendekatan. In alih bahasa, Ahmad Lintang Lazuardi.

Dees, J. G. (2018). The Meaning of Social Entrepreneurship 1,2. Case Studies in Social
Entrepreneurship and Sustainability, 22-30. https://doi.org/10.4324/9781351278560-5

Hulgard, L. (2010). Discourses of social entrepreneurship-Variations of the same theme? EMES European Research Network, 10, 1-21.

http://base.socioeco.org/docs/wp_1001_hul g_rd_web_.pdf\%5Cnhttp://www.emes.net/s ite/wpcontent/uploads/WP_10-

01_Hulgaard_web_pdf

Irianto, A. dan F. (2016). Demografi dan Kependudukan.http://inlislite.dispusip.jakart a.go.id/dispusip/opac/detailopac?id=101985

Jati, W. R. (2015). Bonus Demografi Sebagai Mesin Pertumbuhan Ekonomi: Jendela Peluang Atau Jendela Bencana Di Indonesia? Populasi, 23(1), 1-19. https://doi.org/10.22146/jp.8559

Lak lak Nazhat El Hasanah. (2018). Pengembangan Kewirausahaan Sosial Pada Perguruan Tinggi Melalui Social Project Competition. Pemuda, Jurnal Studi Society, Civil Activ-, Economic Kita, Mimpi, 7, 90-99.

Listyorini, H. (2012). Komponen Dan Dampak Social Entrepreneurship Dalam Upaya Revitalisasi Budaya Dan Industri Batik Lasem. Dinamika Kepariwisataan, XI(2), 4857.

Maryati, S. (2015). Dinamika Pengangguran Terdidik: Tantangan Menuju Bonus Demografi Di Indonesia. Economica, 3(2), 124-136.

https://doi.org/10.22202/economica.2015.v 3.i2.249

Nur Asnawi. (2005). Wirausaha Sebagai Solusi Pengangguran Terdidik Di IndonesiA. 1-21.

Pratomo, D. S. (2017). Fenomena pengangguran terdidik di Indonesia. Sustainable Competitive Advantage, 7(September), 642648.

Putri, L. I. (2017). Reduksi kemiskinan melalui sociopreneurship. VI(1), 48-68.

Santosa, S. P. (2007). Peran Social Entrepreneurship. Dipaparkan Dalam Acara Dialog " Membangun Sinergisitas Bangsa Menuju Indonesia Yang Inovatif, Inventif Dan Kompetitif" Diselenggarakan Oleh Himpunan IESP FE-Universitas Brawijaya,Malang, 14 Mei 2007.

Saputro, A. (2020). Urban Crisis: Produk Kegagalan Urbanisasi di Indonesia. Jurnal Sosiologi Reflektif, 15(1), 173. https://doi.org/10.14421/jsr.v15i1.2000

Suyatna, H., \& Nurhasanah, Y. (2018). Sociopreneurship Sebagai Tren Karir Anak Muda. Jurnal Studi Pemuda, 6(1), 527. https://doi.org/10.22146/studipemudaugm. 38011 
Mey Susanti AS, Implementasi Sociopreneurship Berbasis Lingkungan Sebagai Reduksi

Widiastuti, R., \& Margaretha, M. (2011). Socio Entrepreneurship: Tinjauan Teori Dan Perannya Bagi Masyarakat. Jurnal Manajemen, 11(1), 114870. 